\title{
Helen Salisbury: Social prescribing and the No 17 bus
}

\author{
Helen Salisbury GP \\ Oxford
}

The link between social isolation and poor health has been widely studied, ${ }^{1}$ and intuitively it rings true. If you have only yourself to feed, is there really any incentive to cook a healthy meal? Where's the motivation to go for a walk if you have no one to visit?

In recognition of the fact that the main health problem for many elderly people may be loneliness rather than a statin deficiency, social prescribing is now hugely popular at all levels of the NHS.

We are told that, instead of prescribing yet another pill of dubious marginal benefit, we should send our Practice Care Navigator around to help patients discover new Ways to Wellbeing-be that debt counselling, taking up tai chi, joining Overeaters Anonymous, or starting an art class. The stated aim of most of these projects is to signpost people to voluntary services in their community, which cuts down on cost.

Until last year the No 17 bus would snake its way around the streets of my patch of Oxford. Passengers-most of them elderly_-gathered on street corners, and the bus stopped on request, taking rather a long time to pick them all up before heading into town. But there was no money to be made from the service, and eventually the council decided that it could not afford to subsidise it.

\section{Many older passengers are now effectively housebound or rely on family members to visit and take them out}

No longer do the older residents of the area congregate to wait for the bus and chat, and there's no regular bus driver to ask why she hasn't seen Edna for a week. Lacking transport of their own, many of these older passengers are now effectively housebound or rely on family members to visit and take them out.

Social prescribing may help, and we have seen one or two positive interventions at our practice, but not all people affected by social isolation are in regular contact with their GP. Even if they are, do patients want or feel able to tell their GP that they feel alone and stranded? A bus is a public service for everyone, whereas for many patients a visit from the Practice Care Navigator feels suspiciously like "being done good to." Buses, parks, libraries, children's centres-these are (or were) offered to all without such a connotation, and this public space is the glue that holds our communities together.

Evidence for the efficacy of social prescribing is thin, ${ }^{2}$ with no sign of the rigorous testing before rollout that we would expect from a medical intervention. In a head to head trial, I think that I'd back the No 17 bus.

Competing interests: I am a GP partner, I teach medical students at Oxford University and St Anne's College, Oxford, and I answer readers' medical problems for Take A Break magazine. I am also a member of the National Health Action Party and serve on its national executive committee.

Provenance and peer review: Commissioned; not externally peer reviewed.

1 Courtin E, Knapp M. Social isolation, loneliness and health in old age: a scoping review. Health Soc Care Community 2017;25:799-812. 10.1111/hsc.12311 26712585 Bickerdike L, Booth A, Wilson PM, Farley K, Wright K. Social prescribing: less rhetoric and more reality. A systematic review of the evidence. BMJ Open 2017;7:e013384. 10.1136/bmjopen-2016-013384 28389486

Published by the BMJ Publishing Group Limited. For permission to use (where not already granted under a licence) please go to http://group.bmj.com/group/rights-licensing/ permissions 